\title{
The Development of Cynicism
}

\author{
Candice M. Mills and Frank C. Keil \\ Yale University
}

\section{Abstract}

Two experiments explored the development of cynicism by examining how children evaluate other people who make claims consistent or inconsistent with their self-interests. In Experiment 1, kindergartners, second graders, and fourth graders heard stories with ambiguous conclusions in which characters made statements that were aligned either with or against self-interest. Older children took into account the self-interests of characters in determining how much to believe them: They discounted statements aligned with self-interest, whereas they accepted statements going against self-interest. Experiment 2 examined children's endorsement of three different explanations for potentially self-interested statements: lies, biases, and mistakes. Like adults, sixth graders endorsed lies and bias as plausible explanations for wrong statements aligned with selfinterest; younger children did not endorse bias. Implications for the development of cynicism and children's understanding of bias are discussed.

We all tend to think of young children as naive and gullible. Indeed, some scientists have argued that gullibility in childhood is an evolutionary necessity required to enable children to learn a great deal in a hurry without doubting its content. Dawkins (1993), in describing a 6-year-old, stated such a view with characteristic flair:

When you are pre-programmed to absorb useful information at a high rate, it is hard to shut out pernicious or damaging information at the same time. With so many mindbytes to be downloaded, so many mental codons to be replicated, it is no wonder that child brains are gullible, open to almost any suggestion, vulnerable to subversion, easy prey to Moonies, Scientologists and nuns. Like immune-deficient patients, children are wide open to mental infections that adults might brush off without effort. (pp. 13-14)

But young children may not be completely naive and trusting. They may also have some sense of when to doubt, a drive to detect deceit and distortion that competes with an otherwise trusting nature. Children must eventually acquire some degree of cynicism as they move toward the adult practice of taking things with a grain of salt. In the research we report here, we explored the emergence of cynicism in early childhood. In some circumstances, even young children view the world with a healthy dose of cynicism, and may adjust their views of other people's statements in light of inferred motivations.

Many times, people cannot take what someone says at face value, and they must reflect on the speaker's knowledge, intent, and desires in order to evaluate the validity of the speaker's claims. When do children recognize the importance of these three factors? Even 4-year-olds understand that sometimes people do not have the right knowledge to provide accurate statements, and that others may be ignorant (Baron-Cohen, Leslie, \& Frith, 1985; Sodian, 1988; Wimmer \& Perner, 1983). Young children can use information about the knowledge

Address correspondence to Candice Mills, 2 Hillhouse Ave., Psychology Department, Yale University, New Haven, CT 06511; candice.mills@yale.edu. 
and ignorance of speakers to learn new words (Birch \& Bloom, 2003; Sabbagh \& Baldwin, 2001). Older children understand that people sometimes employ sarcasm and irony, with the intent to mean something different from what is said (Creusere, 1999). Even 4-year-olds understand that speakers sometimes intend to deceive, saying something different from reality in order to get something they want (Bussey, 1992; Robinson, Mitchell, \& Nye, 1995).

The third factor is the focus of the research we report here: How do people's assessments of the impact of desires or self-interests influence their judgments regarding the accuracy of a speaker's statements? Adults certainly think that self-interests and desires influence statements, actions, and beliefs (Miller, 1999). For example, people overestimate the influence of financial compensation on people's willingness to give blood; they also assume that group membership has a large influence on beliefs and attitudes (Miller \& Ratner, 1998). Additionally, people expect that other people are motivationally biased when determining responsibility for positive and negative outcomes, a phenomenon termed naive cynicism (Kruger \& Gilovich, 1999).

These intuitions drive how much adults credit or discredit the beliefs or statements of others. For example, if Michael is a member of one political party and makes an interpretation or a statement in favor of his own party and thus in accord with his self-interest, adults discount his statement (especially if they belong to an opposing party). Likewise, if Michael makes a statement against his own self-interest, adults are more likely to believe him (Murukutla \& Armor, 2003). Much of the research suggests that adults assume that self-interests often unintentionally influence beliefs (a type of bias), as opposed to intentionally affecting what people say (a lie).

How do children move toward these adult intuitions? Little research has explored what children understand about how a desire or self-interest influences what people say or think. However, when children are told a story in which a character either likes or dislikes another character, even kindergartners understand that the character's preferences may influence his or her attributions of blame for ambiguous events involving the other character (e.g., a person who has been accused of breaking an object will be judged more favorably by a friend than by an enemy; Pillow, 1991). Thus, young children may have some understanding that desires, and potentially self-interests, can influence subsequent beliefs or statements, but the extent of that awareness remains unknown.

The experiments presented here address two issues regarding how children assess the impact of self-interests on what people say. First, do children even recognize that self-interests may affect the validity of someone's statements? In Experiment 1, children heard stories in which characters made statements aligned either with or against self-interest. The children were asked how much they believed the characters in question. We predicted that they would consider self-interests in making their judgments of believability.

Second, what mechanism do children endorse for how self-interests might influence what people say? In Experiment 2, children were presented with stories of characters that made wrong statements aligned either with or against self-interest; the children were then asked to choose from three potential explanations for the incorrect statements. These explanations corresponded to those that are often used in other research with adults, referring to lies (motivated, intentional errors in statements), biases (motivated but unintentional errors in beliefs), and mistakes (simple errors not influenced by intentions). Given that children under the age of 7 often overlook the importance of interpretation in shaping people's thoughts and beliefs (Carpendale \& Chandler, 1996; Chandler \& Lalonde, 1996), we predicted that young children might reject bias (an unintentional influence of self-interests on beliefs) as an 
explanation, preferring either lies or mistakes as an explanation of how someone could make an incorrect statement coinciding with or going against self-interest, respectively.

\section{EXPERIMENT 1}

\section{Method}

Participants-Twenty kindergartners (mean age $=6$ years 0 months; range $=5$ years 4 months to 6 years 8 months), 20 second graders (mean age $=7$ years 11 months; range $=7$ years 5 months to 8 years 7 months), and 20 fourth graders (mean age $=9$ years 11 months; range $=8$ years 10 months to 10 years 9 months) participated. The sample was gender balanced and reflected the distribution of ethnic and socioeconomic groups in the community. Children were recruited from the greater New Haven, Connecticut, area and were tested in a quiet room; each session took about 20 min.

Design-Participants heard four kinds of stories, three of each type: with self-interest, against self-interest, truth, and lie. Half of these stories presented a character who would win a prize if certain conditions were met; whether or not these conditions were met was left ambiguous. For instance, in one story, Michael was in a running race, and he and another boy finished the race close together (thus leaving it ambiguous who actually won). For the with-self-interest stories, the main character affirmed that the conditions for him or her to win the prize had been met; for the against-self-interest stories, the character denied that the conditions had been met and claimed that he or she should not win the prize. It was left ambiguous what the main character actually knew about the outcome.

The other half of the stories were nonambiguous. For the truth condition, the character told the truth about his or her achievement, claiming to have won the prize. This kind of story controlled for a preference for people to disbelieve characters who say they won: For these stories, the character was truthful in saying that he or she won, and so participants should have believed the character. For the lie condition, the character lied and claimed not to have won the prize; these stories controlled for a preference to believe characters who say they lost.

All stories were about four sentences long. For counterbalancing, four sets were created, with 12 stories ( 3 of each type) in each, pseudorandomly arranged. The conclusions of the main character were varied (e.g., whether or not he won the race) so that each story served as a with-self-interest story for some sets and as an against-self-interest story in other sets.

Procedure-Prior to testing, participants were trained to use a scale of 1 to 5 stars to rate how much they believed characters in a story, with 1 meaning do not believe at all, and 5 meaning believe completely. Children then heard several examples of statements made by a character named Jeffrey, and they were asked how much they believed each of Jeffrey's statements. All children were able to complete the training successfully, demonstrating an understanding of the different levels of ratings.

After training, participants were told that they would hear some stories, and that they would be asked to think about how much they believed each person. The experimenter then read the stories, periodically asking fact-check questions about the topic of the story and the statement made by the character in question. For each of the 12 stories, a pencil drawing was placed on the table to keep the children's attention. Each drawing referred to the topic of the story (e.g., a swimming competition, a bug collection), but did not provide any information about the outcome of the event. For instance, for the story about a swimming competition, the drawing depicted an empty swimming pool with lanes. Following each story, 
participants were asked to use the scale to rate how much they believed the main character in that story. They were then asked to explain why they chose that number.

\section{Results and Discussion}

For each story type (with self-interest, against self-interest, truth, and lie), we calculated the average rating across stories for children in each grade. See Figure 1 for participants' responses for the different story types.

A repeated measures analysis of variance (ANOVA) with story type as a within-subjects variable and grade as a between-subjects variable showed a significant effect of story type, $F(3,171)=119.91, p<.001, \eta^{2}=.678$. We also found a Story Type $\times$ Grade interaction, $F(6$, 171) $=4.728, p<.001, \eta^{2}=.142$.

As expected, all participants rated the believability of the characters in the truth scenarios higher than the believability of the characters in the lie scenarios, $t(59)=19.556, p<.001, d$ $=3.681$. Second and fourth graders believed characters in the against-self-interest scenarios significantly more than those in the with-self-interest scenarios, $t(19)=5.900, p<.001, d=$ 1.140 , and $t(19)=2.471, p<.05, d=0.689$, respectively. Thus, these children thought characters who made statements against their self-interest were more believable than characters who made statements with their self-interest.

Kindergartners, however, showed the opposite pattern: They believed the statements aligned with self-interest more than the statements going against self-interest, $t(19)=2.251, p<.05$, $d=0.548$. According to many of their explanations, the kinder-gartners seemed to assume that someone who wants to win a prize or achieve a goal will do so. We touch on this finding again in the General Discussion.

In sum, even second graders are somewhat cynical in thinking about how self-interests influence what people say: They are less likely to believe statements consistent with selfinterest than to believe statements against self-interest. But how do children come to think self-interests influence beliefs and statements? The explanations the children provided to justify their judgments offer some insight into this question. The children's explanations fell into three main categories: The character lied (made motivated, intentional errors in his or her statement), was biased (had erroneous beliefs that were motivated but unintentional), or made a mistake (made a simple error not influenced by intentions). From this study alone, however, it is difficult to draw conclusions regarding children's intuitions about the likelihood of each of these possible explanations of how self-interest influences beliefs and statements.

In Experiment 2, we followed up on these issues, providing children with similar stories, except that we explicitly pointed out that each character made an incorrect statement about the outcome of a competition (as opposed to leaving the outcome unclear). The children were then asked to choose between three potential explanations for why the character made that statement: The character lied, had a bias, or made a mistake. When adults are asked to provide explanations for similar types of stories, they prefer to explain incorrect statements in accord with self-interest as being the result of lies and bias, but see incorrect statements against self-interest as mistakes (Mills, Keil, \& Effron, 2004). We predicted similar results with children, although we were unsure how often young children would endorse bias as an explanation. 


\section{EXPERIMENT 2}

\section{Method}

Participants-Twenty kindergartners (mean age $=5$ years 5 months; range $=4$ years 9 months to 6 years 3 months), 20 second graders (mean age $=7$ years 5 months; range $=6$ years 11 months to 9 years 2 months), and 20 fourth graders (mean age $=9$ years 8 months; range $=9$ years 2 months to 11 years 9 months) participated. Additionally, 20 sixth graders (ages 11 or 12 years) completed a pencil-and-paper version of the task. Once again, the sample was gender balanced and reflected the distribution of ethnic and socioeconomic groups in the community. Recruitment methods were identical to those used in Experiment 1.

Design-Each participant heard or read two kinds of stories, three of each type: with selfinterest and against self-interest. These stories were similar to the stories in Experiment 1: Two characters that were friends were in a competition with uncertain results, and one character made a statement about the outcome of the competition; this statement was aligned either with or against self-interest. The knowledge state of the main character was once again not addressed in these stories, as we wanted to leave that open for interpretation (so as to allow for the children to posit mental states compatible with lies, biases, and mistakes). The counterbalancing methods from Experiment 1 were used.

Unlike in the first study, after the character made a claim about the outcome, the stories ended with a statement saying that the character was incorrect. For example, in the withself-interest version of the running-race story, after the character claimed that he came across the finish line ahead and so should win the prize, the next statement said that the character was really wrong, that he came across the finish line behind his friend and so should not win.

For each story, participants were asked to choose the best explanation for the character's wrong statement. One explanation indicated that the character lied: The character knew he or she was wrong, but said differently to try to achieve a goal ("Michael knew he crossed the finish line behind his friend, but he said he was ahead because he wanted to win. His wanting to win made him try to trick his friend."). Another explanation indicated that the character was biased: The character's desire to get the prize made him or her misperceive the situation ("Because Michael wanted to win the race, he really thought that he finished ahead. His wanting to win made him think he finished ahead of his friend."). A third explanation indicated that the character made a mistake: Self-interest played no role in the character's error, but for some other reason (such as physical perspective or failure of attention), he or she misperceived the situation ("Because Michael just made a mistake, he really thought he had finished ahead. It was just a mistake: He could have just as easily thought he was behind.").

Each story was accompanied by six pictures. Three pictures depicted the story itself, representing the two characters in the story, what the main character said, and what really happened. The other three pictures, shown in two frames each, represented the three choices for explanations for the character's wrong statement. Sample pictures are available on the Web (http://pantheon.yale.edu/ cmm55/cynicism.htm).

Procedure-Each experimental session began with a short training session aimed at introducing the children to the kinds of pictures that would accompany the stories. Next, the experimenter provided an example of bias, reading a story involving a character who really wanted a valentine, and who thought a pink envelope in her mailbox was a valentine for her, even though it was for her mother. The children were then given an example of a lie (Jeffrey 
knew that he broke his mother's favorite lamp, but said his dog broke it) and an example of a mistake (Jorge, playing hide-and-seek with a friend, mistakenly thought his friend was behind one box when he was really behind the other). The children were asked to explain what happened in each story so the experimenter could make sure they understood the example; if they did not, the experimenter reread the story. All examples were accompanied by pictures, which were described as just being there to help the children keep track of what was being said.

The children were then told that they were going to listen to some stories and answer some questions. At the beginning of each story, the experimenter introduced the characters in the story, displaying a picture with two stick-figure people wearing shirts of different colors. The children then heard the rest of the story. For example, Michael was in a running race, and he and another boy finished the race close together. The children were then told, "Michael says to the judge that he came across the finish line ahead, and so he should win. But Michael was wrong - he really crossed the finish line behind, and he should not win." Two additional pictures were placed on the table: one depicting what Michael said (with a speech bubble) and a second depicting what really happened.

The children were frequently asked fact-check questions regarding the topic of the story, what the character said, and what really happened. They then heard the three potential explanations (in random order) for why the character made the incorrect statement. For each explanation, a picture was displayed. The children were asked to point to the best explanation.

The sixth-grader pencil-and-paper version included a set of written instructions with the accompanying examples from the experimenter's script. Each of the stories was presented on a separate page, along with small versions of the corresponding pictures. Participants indicated their response by checking off a box next to their answer.

\section{Results}

The number of endorsements was calculated for each type of explanation (lie, bias, and mistake) for both with-self-interest and against-self-interest stories (see Fig. 2). A repeated measures ANOVA with grade as a between-subjects factor and story type (with self-interest and against self-interest) and explanation type (lie, bias, and mistake) as within-subjects factors showed a main effect of explanation in that children preferred lies and mistakes as explanations more often than biases, $F(2,152)=26.440, p<.001, \eta^{2}=.193$. There was a significant interaction between story type and explanation type, $F(2,152)=69.054, p<$. $001, \eta^{2}=.476$. There was also a trend toward an interaction of story type, explanation type, and grade, $F(6,152)=1.860, p=.057, \eta^{2}=.076$.

To examine the differences in average number of endorsements as a function of the story type, we conducted separate repeated measures ANOVAs for with-self-interest and againstself-interest stories. For against-self-interest stories, there was a significant difference across explanation types, $F(2,152)=54.644, p<.001, \eta^{2}=.418$. There was no explanation-bygrade interaction. The children chose mistakes significantly more than biases or lies for these stories, $t(79)=6.443, p<.001, d=1.993$, and $t(79)=10.796, p<.001, d=1.357$. The children also endorsed lies more often than biases, $t(79)=2.446, p<.050, d=.428$.

For with-self-interest stories, there was a significant difference across explanation types as well, $F(2,152)=23.292, p<.001, \eta^{2}=.235$. In general, children endorsed lies significantly more than biases or mistakes, $t(79)=5.188, p<.001, d=1.03$, and $t(79)=5.883, p<.001$, $d=1.162$, respectively. There was no significant difference between biases and mistakes, $t(79)=0.774, p=.441$. 
For the with-self-interest stories, there was also a trend for an explanation-by-grade interaction, $F(6,152)=2.113, p=.136, \eta^{2}=.061$. Given that young children rarely endorsed biases as an explanation for with-self-interest stories, we wanted to see if the endorsement of bias varied across development. While kindergartners, second graders, and fourth graders endorsed lies more often than biases, $t(19)=3.488, p<.005, d=1.413 ; t(19)$ $=3.835, p<.005, d=1.319$; and $t(19)=3.857, p=.001, d=1.615$, respectively, sixth graders chose both lies and biases, not preferring either of these explanations to the other, $t(19)=0.603, p=.554$.

\section{GENERAL DISCUSSION}

By second grade, children hold the same intuitions as adults about how self-interests influence interpretations. They doubt individuals making statements in accord with selfinterests, whereas they increase their belief of individuals making statements against selfinterests. In addition, even young children intuitively explain self-interested incorrect statements in terms of lies, while explaining incorrect statements against self-interest in terms of mistakes. In a sense, young children seem to be even more cynical than adults in this task, assuming that people must be intentionally misleading others even when they may not be.

Understanding of unintentional influences on beliefs or statements shows considerable development. Although children occasionally offered bias as an explanation during the exploratory questioning for Experiment 1, kindergartners through fourth graders rarely endorsed bias as the best possible explanation for the stories in Experiment 2. The concept of bias may therefore be difficult to grasp early on. It is not until sixth grade that children begin to endorse lies and biases as equally plausible explanations for self-interested incorrect statements. An understanding of unconsciousness develops over the elementaryschool years (Flavell, Green, Flavell, \& Lin, 1999), and it may be difficult for children to grasp this concept and its causal influences. Future research should explore the emergence of an understanding of bias in children.

In sum, people's beliefs and statements are not always accurate. People may attempt to deliberately deceive others, they may be influenced by biases that they are not even aware of, or they may simply be mistaken. Adults are clearly sensitive to all three sources of inaccuracy and use information about a speaker's self-interests to adjust their interpretations of a speaker's message. The ability to make such adjustments starts to emerge quite early in development, but it does not first appear in the adult form. Young children are less likely than adults to give people who make incorrect statements in their own favor the benefit of the doubt, assuming instead that these kinds of inaccuracies arise from a malicious intent to deceive. In addition, kindergartners may think that really wanting an event to be true increases the likelihood that it is correct to state that it is true, apparently being strongly influenced by a desire for there to be a congruence between desired outcomes and actual outcomes. Children may be more gullible than adults and may at first assume that if one really wants something to be true, it probably is; but the seeds of doubt are also present from an early age and develop dramatically in the elementary-school years.

\section{Acknowledgments}

This research was supported in part by National Science Foundation Graduate Research Fellowship to Candice Mills and by National Institutes of Health Grants R01-HD23922 and R-37-HD023922 to Frank Keil. We thank the staff, parents, and students of Bethany Community School, Strong School, and Kennedy Middle School and the families who brought children into our lab. For insightful comments or feedback on previous drafts, we also thank Paul Bloom, David Armor, Daniel Effron, and members of the Yale Cognition and Development Laboratory, as well as James Cutting and two anonymous reviewers. 


\section{References}

Baron-Cohen S, Leslie AM, Frith U. Does the autistic child have a 'theory of mind'? Cognition. 1985; 21:37-46. [PubMed: 2934210]

Birch SAJ, Bloom P. Children are cursed: An asymmetric bias in mental-state attribution. Psychological Science. 2003; 14:283-286. [PubMed: 12741755]

Bussey K. Lying and truthfulness: Children's definitions, standards, and evaluative reactions. Child Development. 1992; 64:1005-1021.

Carpendale JI, Chandler MJ. On the distinction between false belief understanding and subscribing to an interpretive theory of mind. Child Development. 1996; 67:1686-1706.

Chandler, MJ.; Lalonde, C. Shifting to an interpretive theory of mind: 5- to 7-year olds' changing conceptions of mental life. In: Sameroff, A.; Haith, M., editors. Reason and responsibility: The passage through childhood. Chicago: University of Chicago Press; 1996. p. 111-139.

Creusere MA. Theories of adults' understanding and use of irony and sarcasm: Applications to and evidence from research with children. Developmental Review. 1999; 19:213-262.

Dawkins, R. Viruses of the mind. In: Dahlbom, B., editor. Dennett and his critics: Demystifying mind. Oxford, England: Blackwell; 1993. p. 13-27.

Flavell JH, Green FL, Flavell ER, Lin NT. Development of children's knowledge about unconsciousness. Child Development. 1999; 70:396-412. [PubMed: 10218262]

Kruger J, Gilovich T. "Naïve cynicism” in everyday theories of responsibility assessment: On biased assumption of bias. Journal of Personality and Social Psychology. 1999; 75:743-753.

Miller DT. The norm of self-interest. American Psychologist. 1999; 54:1053-1060. [PubMed: 15332526]

Miller DT, Ratner RK. The disparity between the actual and assumed power of self-interest. Journal of Personality and Social Psychology. 1998; 74:53-62. [PubMed: 9457775]

Mills, CM.; Keil, FC.; Effron, DA. Unpublished manuscript. Yale University; New Haven, CT: 2004. Self-other differences in explanations of bias.

Murukutla, N.; Armor, DA. Unpublished manuscript. Yale University; New Haven, CT: 2003. Illusions of objectivity in the dispute between India and Pakistan over Kashmir.

Pillow BH. Children's understanding of biased social cognition. Developmental Psychology. 1991; 27:539-551.

Robinson EJ, Mitchell P, Nye R. Young children's treating of utterances as unreliable sources of knowledge. Journal of Child Language. 1995; 22:663-685. [PubMed: 8789518]

Sabbagh MA, Baldwin DA. Learning words from knowledgeable versus ignorant speakers: Links between preschoolers' theory of mind and semantic development. Child Development. 2001; 72:1054-1070. [PubMed: 11480934]

Sodian B. Children's attributions of knowledge to the listener in a referential communication task. Child Development. 1988; 59:378-385.

Wimmer H, Perner J. Beliefs about beliefs: Representation and constraining function of wrong beliefs in young children's understanding of deception. Cognition. 1983; 13:103-128. [PubMed: 6681741] 


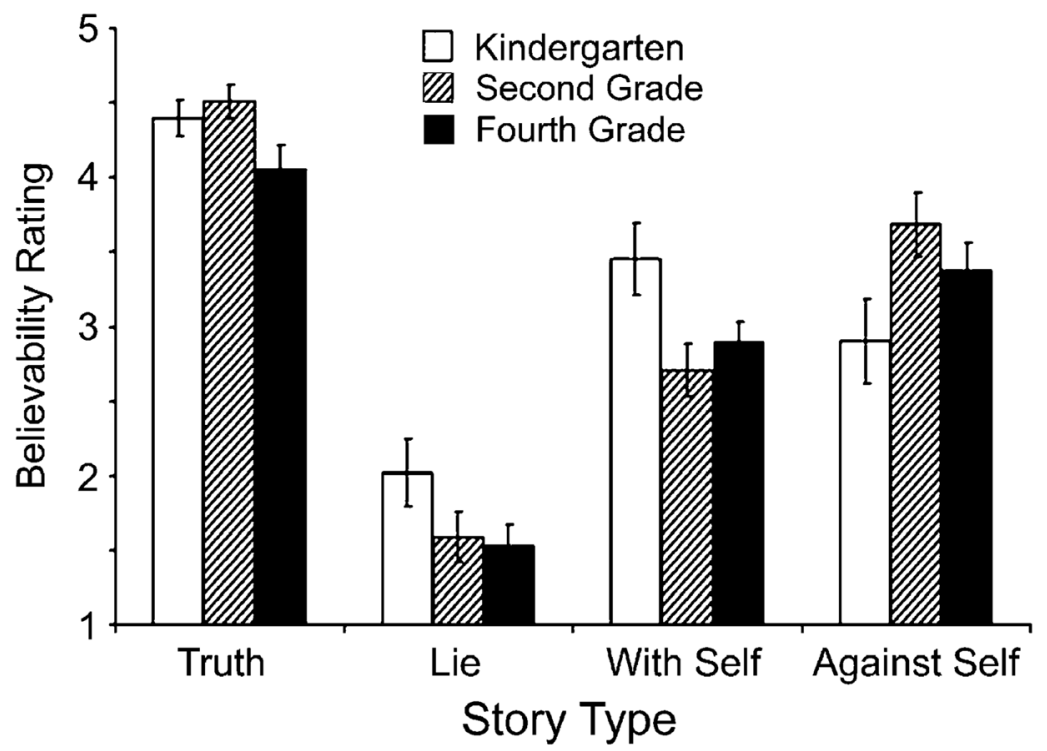

Fig. 1.

Results of Experiment 1: children's ratings for believability of statements of truths and lies, as well as statements with and against self-interest. 


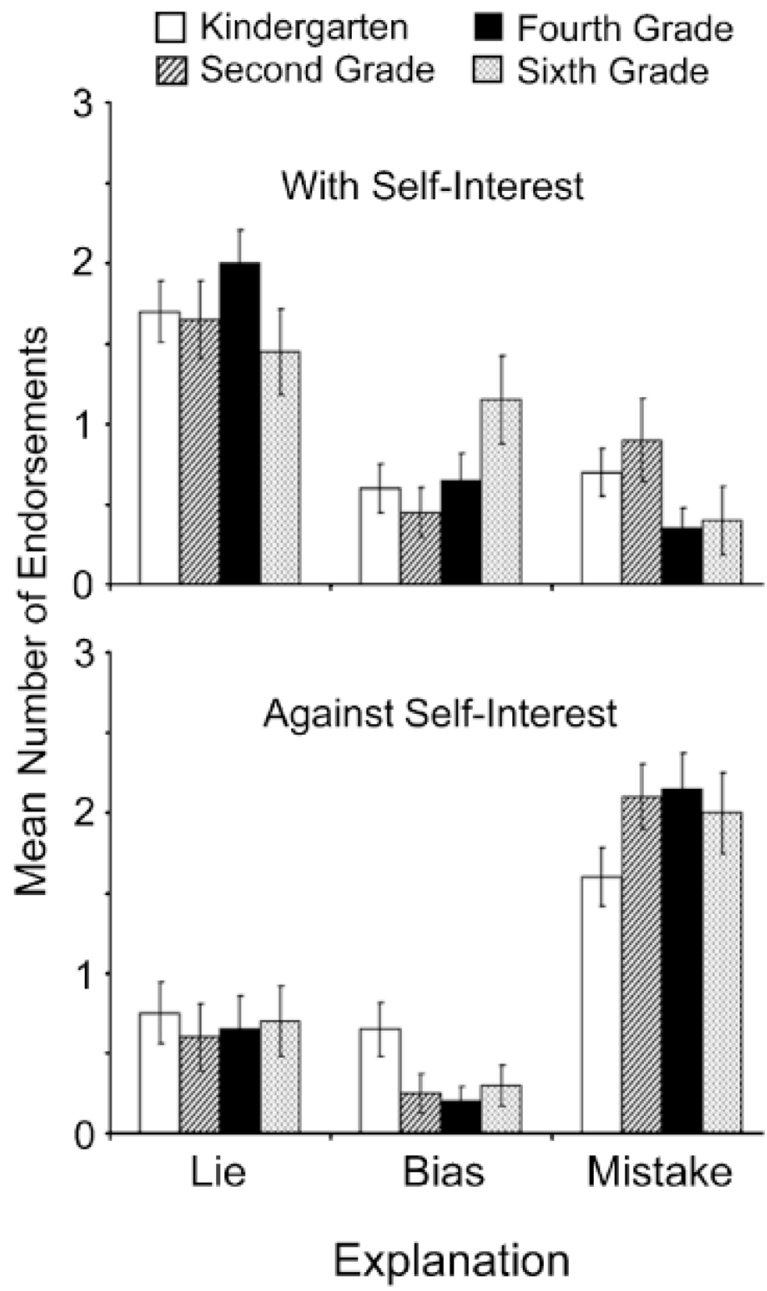

Fig. 2.

Results of Experiment 2: children's average number of endorsements of lies, biases, and mistakes as explanations for wrong statements aligned with self-interest (top panel) and going against self-interest (bottom panel). 